\title{
Microbiology Aspects of Rhinosinusitis
}

\author{
Agnieszka Magryś, Jolanta Paluch-Oleś and Maria Kozioł-Montewka \\ Department of Medical Microbiology, Medical University of Lublin, \\ Poland
}

\section{Introduction}

Rhinosinusitis with its chronic benign course, failure in antibiotic treatment and acute exacerbations, usually require multiple courses of antibiotics or surgical procedures, or both. Nowadays, the pathogenic mechanisms of microbes in rhinosinusitis have gradually been revealed. Many current hypotheses focus on the formation of biofilms, bacterial superantigens, cytokine dysregulation, and abnormalities of cell-mediated immune responses (Kilty \& Desrosiers, 2008; Zhang et al., 2005, Post et al., 2004).

"Rhinosinusitis" is a group of disorders characterized by inflammation of the mucosa of the nose and the paranasal sinuses. It is presently accepted that rhinosinusitis is initiated with an inflammatory insult (viral infection of upper respiratory tract, allergic rhinitis, etc.), followed by bacterial or fungal superinfection (Kennedy \& Thaler, 1997; van Cauwenberge et al., 2006). Most upper respiratory tract infections are self-limited but progression to acute illness occurs and progression to chronic disease is common. Because specific treatment approaches are crucial for the different types of rhinosinusitis, this review focuses on microbiological aspects of rhinosinusitis.

\section{Normal flora of upper respiratory tract}

Most of the surfaces of the upper respiratory tract (including nasal and oral passages, nasopharynx, oropharynx, and trachea) are colonized by normal flora. The normal flora of human upper respiratory tract is harmless, and usually beneficial for the host. Two main functions are played by these bacteria, that are important in maintaining the healthy state of the host:

1. these organisms compete with pathogenic organisms for potential attachment sites,

2. they often produce substances (toxins or acids) which are bactericidal.

The nose is colonized predominantly by staphylococci, with Staphylococcus aureus and Staphylococcus epidermidis and diphtheroids as the leaders. The most important group of microorganisms native to oropharynx are also the alpha-hemolytic streptococci or viridans streptococci. This group includes Streptococcus mitis, Streptococcus mutans, Streptococcus milleri, and Streptococcus salivarius. It is believed that these bacteria act as antagonists against invasion by pathogenic streptococci.

But normal nasopharynx is not only the primary settlement of saprophytic bacteria. It is also the chief carrier of common respiratory pathogens, including Streptococcus pneumoniae, Haemophilus influenzae and Moraxella catarrhalis (Baron 1996). 


\section{Acute rhinosinusitis. Epidemiology and predisposing factors}

\subsection{Definition}

Sinusitis is inflammation of the sinuses, which are air-filled cavities in the skull. This inflammation leads to blockade of the normal sinus drainage pathways (sinus ostia), which in turn leads to mucus retention, hypoxia, decreased mucociliary clearance, and predisposition to bacterial growth. Acute rhinosinusitis is an inflammatory condition involving the paranasal sinuses, as well as the lining of the paranasal passages, and it lasts up to 4 weeks, after which the symptoms resolve completely. Sinus infection is defined as the invasion and multiplication of microorganisms within a sinus. The etiology can be infectious (bacterial, viral, or fungal) or noninfectious (allergic) triggers (Fokkens et al., 2007; Thaler \& Kennedy, 2008).

European Position Statement on Rhinosinusitis and Nasal Polyps defines acute rhinosinusitis as sudden onset of two or more symptoms, one of which should be either nasal blockade/obstruction/congestion or nasal discharge (anterior/posterior nasal dip) with facial pain/pressure or reduction or loss of smell (Fokkens et al., 2007).

\subsection{Pathogenic factors of acute rhinosinusitis}

Acute rhinosinusitis occurs when one of the mechanisms essential to sinus clearance breaks down. The ostiomeatal complex is particularly vulnerable to inflammatory changes, swelling and obstruction. Anatomic variations and other factors generally predispose patients to acute bacterial rhinosinusitis by causing inflammation in the ostiomeatal complex. Normal ciliary function, intact mucous membranes and normal mucous production are required for sinus clearance. Many factors can disturb these functional mechanisms predisposing to acute infection (Kennedy \& Thaler, 1997; Anon, 2005; Fokkens et al., 2007).

The initial stages of rhinosinusitis comprise inflammatory swelling of the sinus epithelium and mucosa, secretion of proinflammatory factors, including cytokines, accumulation of inflammatory cells, such as eosinophils and lymphocytes, and obstruction of the sinus ostia (Hadley \& Siegert, 2004).

Data shows that viral upper respiratory tract infections and pharyngeal colonization with group A streptococci predispose children to acute bacterial rhinosinusitis. The incidence of viral infections in acute rhinosinusitis is unknown, but it is estimated that $0.5-5 \%$ of viral infections lead to sinusitis (Brook et al., 2000; Fokkens et al., 2007).

Normal mucociliary flow is a key defense mechanism in the prevention of acute rhinosinusitis. Viral rhinosinusitis results in the loss of ciliated cells and mucociliary flow during the first week of infection. Consequently, the impaired mucociliary function during viral rhinosinusitis increases the risk of bacterial superinfection, which, in turn, results in further disruption of mucociliary flow (Fokkens et al., 2007; Sande \& Gwaltney 2004). Exposure to bacterial toxins can also reduce ciliary function. Approximately $10 \%$ of cases of acute rhinosinusitis result from direct inoculation of the sinus with a large amount of bacteria. Bacterial infection causes inflammation and swelling, which leads to increased mucus production, reduced air flow through the nasal cavity and mucus congestion in the sinuses, enhancing bacterial growth (Hadley \& Siegret, 2004). 
Allergy is another factor that predispose to rhinosinusitis. Allergy can contribute to rhinosinusitis through either nasal congestion and subsequent ostial obstruction or direct allergic effects on sinus-lining cells. Obstructed sinus ostia, as the results of mucosal swelling and edema, may be more prone to infection (Fokkens et al., 2007; Thaler \& Kennedy, 2008).

The other factors that predispose to acute rhinosinusitis are nasal polyposis, deviation of the nasal septum and dental procedures. Air pollution, cigarette smoking and overuse of topical decongestants impair ciliary action and predispose to rhinosinusitis as well (Fokkens et al., 2007).

\subsection{Microbiology of acute rhinosinusitis: Viral or bacterial?}

The upper respiratory tract represents a frequent site of infection because it is regularly exposed to direct contact and transmission of environmental pollutants and common microbes during breathing.

The most common factor associated with rhinosinusitis is upper respiratory infection, which is complicated by bacterial infection. Upper respiratory infections are mainly caused by viruses, leading to symptoms of common cold and inflammation of the paranasal sinuses. Viral rhinosinusitis has seasonal patterns of occurrence based on the virus involved. Rhinovirus is the most common cause of common cold and rhinosinusitis in all age groups, accounting for $30-70 \%$ of all respiratory illnesses. Other viruses causing upper respiratory infections are coronaviruses (7-18\%), followed by influenza A and B, adenoviruses, parainfluenza viruses, respiratory syncytial viruses (RSV) and enteroviruses, all accounting for minor proportions of common cold cases (Thaler \& Kennedy, 2008). Viral upper respiratory tract infection stimulates increases in inflammation and in the local immune response of the nasopharynx and surrounding mucosa. Some viruses, such as influenza virus, produce significant mucosal damage. Others promote the local production of cytokines and other inflammatory mediators, leading to the signs and symptoms of the common cold (Aanan, 2005). Clinically, patients experience a self-limiting illness lasting 3-7 days.

Acute bacterial rhinosinusitis complicates approximately $0.5 \%$ of adult and $5 \%$ pediatric cases of viral infections. It is usually a secondary infection resulting from ostiomeatal complex obstruction, impaired (delayed or absent) mucociliary clearance and weakened mucociliary integrity caused by an acute viral upper respiratory tract infection (Sande \& Gwaltney, 2004).

Acute bacterial rhinosinusitis is a clinical condition characterized by nasal congestion, purulent rhinorrhea, postnasal dip and facial pain and pressure alone or with associated referred pain of the ears or teeth. The syndromes last for 7-14 days but no more than 4 weeks (Fokkens et al., 2007).

Several factors may predispose an individual with viral rhinosinusitis to acquire a secondary bacterial infection, including viral virulence, nosopharyngeal colonization and host immunity. The role of bacteria in acute rhinosinusitis is well defined. Streptococcus pneumoniae (20\%-45\%) and non typable strains of Haemophilus influenzae (22\%-35\%), are the most common pathogenic organisms in acute bacterial rhinosinusitis in adults. Streptococcus 
pneumoniae (30\%-45\%), non typable Haemophilus influenzae (20\%-28\%) and Morraxella catarrhalis $(20-28 \%)$ are reported as predominant in children with acute bacterial rhinosinusitis. Until now Staphylococcus aureus has often been considered as a contaminant, but a recent data suggests that Staphylococcus aureus is a true pathogen in about $10 \%$ of cases of acute bacterial rhinosinusitis in adults (Benninger \& Manz 2010; Payne, 2007) (Table 1). This is not surprising, as all these pathogens can be the parts of normal flora in upper respiratory tract.

The growing resistance to antimicrobial agents of all respiratory tract bacterial pathogens has made the management of bacterial rhinosinusitis more difficult.

Streptococcus pneumoniae are gram-positive, catalase-negative, facultatively anaerobic cocci that account for up to $45 \%$ of acute bacterial rhinosinusitis cases in adults and children. The rise of antimicrobial resistance in Streptococcus pneumoniae is a major concern. The most alarming situation is the occurrence of strains with decreased susceptibility to penicillin, that was the drug of choice in pneumococcal infections for many years. Penicillin resistance means the resistance or decreased susceptibility to other $\beta$-lactams. This is applied mostly for cephalosporins. Moreover, strains resistant to penicillin are also multi-drug resistant (resistance to macrolids, tetracycline, co-trimoxazole). However, they are still susceptible to increased doses of amoxicillin (Mazur, 2010; Aanan 2005).

Haemophilus influenzae is the second commonest agent of bacterial acute rhinosinusitis responsible for about $25 \%$ of rhinosinusitis cases in children. Studies have reported the presence of this bacterium in up to a third of adult rhinosinusitis patients as well. Betalactamase production is the mechanism of antimicrobial resistance for this organism. Of isolates from the paranasal sinus, $32.7 \%$ were found to be $\beta$-lactamase-positive. Other reports suggest a rate of $44 \%$.

Moraxella catarrhalis is mainly isolated from children. Over $75 \%$ of all children harbor this bacterium, which causes about $25 \%$ of rhinosinusitis cases. The strains of Moraxella catarrhalis commonly (more than $90 \%$ strains) produce $\beta$-lactamases all over the world (Mazur, 2010; Aanan, 2005).

The widespread antibiotic resistance among pathogens that are agents of rhinosinusitis allows for the persistence of infection and the development of chronic rhinosinusitis (CRS) (Thaler \& Kennedy, 2008).

Nowadays it is noted that the vaccination of children with heptavalent conjugate pneumococcal vaccine results in significant shift in causative pathogens of acute bacterial rhinosinusitis. While the proportion of Streptococcus pneumoniae declined by $11 \%$, the proportion of Haemophilus influenzae increased by 6\%. A small increase in the isolation of other pathogens (Moraxella catarrhalis, Staphylococcus auresus and Streptococcus pyogenes) was also noted (Brook et al., 2006). Widespread use of conjugate pneumococcal vaccine has led to decreasing incidence of pneumococcal acute bacterial rhinosinusitis, which may have implications for treatment recommendations for these infections (Benninger, 2008). This pathogen shift may also have an important effect on the severity of acute bacterial rhinosinusitis. It is documented, that patients with acute bactericidal rhinosinusitis infected with Streptococus pneumoniae have more significant symptoms and worse radiographic 
findings than those infected with Haemophilus influenzae. This fact could result in less severe symptoms and radiographic findings in patients with acute form of the disease (Benninger \& Manz, 2010).

\begin{tabular}{|c|c|c|}
\hline \multirow{3}{*}{ Pathogens } & \multicolumn{2}{|c|}{ Percentages } \\
\hline & \multirow{3}{*}{ Adults } & \multirow{3}{*}{ Children } \\
\hline & & \\
\hline Viruses & & \\
\hline Rhinovirus & $15 \%-40 \%$ & $1 \%$ \\
\hline Adenovirus & ---- & $2 \%$ \\
\hline Influenzae virus & $5 \%$ & ---- \\
\hline Parainfluenzae virus & $3 \%$ & $2 \%$ \\
\hline \multicolumn{3}{|l|}{ Bacteria } \\
\hline Streptococcus pneumoniae & $20 \%-45 \%$ & $30 \%-45 \%$ \\
\hline Haemophilus influenzae & $22 \%-35 \%$ & $20 \%-28 \%$ \\
\hline Moraxella catarrhalis & $0 \%-8 \%$ & $20 \%-28 \%$ \\
\hline Staphylococcus aureus & $0 \%-10 \%$ & $0 \%-8 \%$ \\
\hline Streptococcus pyogenes & $0 \%-7 \%$ & $3 \%-9 \%$ \\
\hline
\end{tabular}

* non typable strains

Table 1. The commonest pathogens in acute rhinosinusitis. Data are from (Thaler \& Kennedy, 2008; Sande \& Gwaltney, 2004).

\subsection{Microbiology diagnostics of acute rhinosinusitis}

Bacterial and viral rhinosinusitis are difficult to differentiate on clinical grounds. On the other hand, bacterial rhinosinusitis must be distinguished from viral infection and treated 
with antibiotics, because serious complications may be associated when bacterial superinfection develops. (Hytönen et al., 2000; Herrmann \& Forsen 2004). The reference standard for the diagnosis of acute bacterial rhinosinusitis is sinus puncture with culture and recovery of bacteria in high density ( $\geq 10^{4}$ colony forming units $/ \mathrm{mL}$ ) (Hart, 2007). Although sinus aspiration with the possible bacterial culture is the "gold standard" for the diagnosis of acute bacterial rhinosinusitis, it is not recommended in general practice. The reasons are that the procedure is invasive, time-consuming and potentially painful for the patient and can only be performed by a specialist as it requires a local anestethic. However, the results of sinus aspiration correlate with clinical and radiographic findings in patients with acute respiratory symptoms.

The most widely used diagnostic procedures for acute rhinosinusitis are signs and symptoms, supported by radiographic findings. Some experts believe that bacteriological cultures from the posterior parts of nasal cavity and nasopharyngeal aspirates best identify those patients with bacterial superinfection (Anan, 2005).

Because of the difficulty associated with distinguishing viral from bacterial rhinosinusitis, the diagnosis of acute bacterial rhinosinusitis is mostly reserved for patients who experience rhinosinusitis symptoms (eg, sinus pain, tooth pain, nasal congestion) for more than 7 days (Hart, 2007).

\subsection{Current recommendations for diagnosing acute rhinosinusitis in children}

Although sinus aspiration is the "gold standard" for the diagnosis of acute bacterial rhinosinusitis, it is not recommended method for routine diagnosis of bacterial sinus infections in children. According to recommendations of American Academy of Pediatrics the diagnosis of acute bacterial rhinusitis is based on clinical criteria in children who present with upper respiratory symptoms that are either persistent or severe (American Academy of Pediatrics, 2001).

Persistent symptoms are symptoms of upper respiratory tract infection that last longer than 10 days to 14 days, but less than 30 days. Such symptoms include nasal or postnasal discharge, daytime cough (which may be worse at night), or both.

Severe symptoms include a temperature of at least $39^{\circ} \mathrm{C}$ and purulent nasal discharge present concurrently for at least 3 to 4 consecutive days in a child who seems ill. In this clinical presentation, the duration of symptoms is not important, and antimicrobial treatment is recommended to be started as soon as possible (American Academy of Pediatrics, 2001).

American Academy of Pediatrics has taken the position that, in children six years and younger who are at the peak age for developing acute bacterial sinusitis, a diagnosis can be made without performing imaging studies. However, controversy exists about the need for radiographs to confirm acute sinusitis in children older than six years with persistent symptoms and for children of any age with severe symptoms (American Academy of Pediatrics, 2001). The American College of Radiology recommends that the diagnosis be made on clinical criteria and that radiographs be used only in patients who do not recover or who worsen during the course of antimicrobial therapy (McAlister et al., 2000). 
CT scans of the paranasal sinuses should be performed only when surgery is being considered. CT scans are indicated in children with complications of acute bacterial sinus infection or those with very persistent or recurrent infections that are not responsive to medical therapy (McAlister et al., 2000; American Academy of Pediatrics, 2001).

\section{Chronic rhinosinusitis}

\subsection{Definition}

Chronic rhinosinusitis can be defined as a group of disorders characterized by inflammation of the mucosal lining of the nasal cavity and para-nasal sinuses lasting for at least 12 weeks. Symptoms are much more subtle then with acute rhinosinusitis. In order to diagnose chronic rhinosinusitis, patients are required to have 2 of the following symptoms for at least 12 consecutive weeks: (1) anterior and /or posterior mucopurulent drainage, (2) nasal obstruction and (3) hyposmia or anosmia but also objective evidence of sino-nasal inflammation on both endoscopy and radiological imaging with computerised tomography. Fever is not typically observed. According to the definitions of the European Position Paper on Rhinosinusitis and Nasal Polyps, chronic rhinosinusitis and nasal polyposis are considered as one disease entity, in which nasal polyposis forms a subgroup of chronic rhinosinusitis (Fokkens et al., 2007).

Chronic rhinosinusitis is mostly diagnosed in association with predisposing conditions such as asthma, allergy, dental disease, cystic fibrosis, polyposis and immunodeficiency syndrome (Thaler \& Kennedy, 2008; Kennedy \& Thaler, 1997).

It has been postulated that chronic rhinosinusitis evolves from acute rhinosinusitis, but this has never been definitively proven. Also, the role of bacterial infection in chronic rhinosinusitis is less clear than in acute rhinosinusitis (Thaler \& Kennedy, 2008).

\subsection{Pathogenic factors}

Chronic rhinosinusitis is now considered a multi-factorial disease involving multiple host and environmental factors. This factors has been broadly categorized into extrinsic or non-host related factors and intrinstic or host related factors. Extrinsic factors that have been implicated as etiologies contributing to the development of CRS include viral, bacterial, and/or fungal colonization and their associated pathogenicity (biofilms, superantigens, osteitis and non-IgE mediated eosinophilic inflammation) as well as exposure to inhaled substances, such as cigarette smoke or allergens. Intrinsic factors found to be associated with chronic rhinosinusitis include anatomic/structural abnormalities, genetic abnormalities, such as cystic fibrosis or primary ciliary dyskinesia and disorders in innate and cell mediated immune system (van Cauwenberg \& van Hoeche, 2006).

The presence of intracellular Staphylococcus aureus in epithelial cells of the nasal mucosa has been suggested to play a significant risk for recurrent episodes of rhinosinusitis due to persistent bacterial clonotypes, which appear refractory to antimicrobial and surgical therapy (Plouin-Gaudon et al., 2006). 


\subsection{Bacteria and chronic rhinosinusitis}

The microbiology of chronic rhinosinusitis differs when comparing to acute rhinosinusitis. Study shows that in patients with chronic rhinosinusitis, pathogens such as Staphylococcus aureus, coagulase negative streptococci and anaerobic Gram-negative bacteria replace the pathogens commonly found in bacterial acute rhinosinusitis. The prevalence of anaerobic species can be explained by physiologic changes in the sinuses including reduced oxygen tension and $\mathrm{pH}$, thereby creating a favorable environment for these organisms (van Cauwenberge et al., 2006; Thaler \& Kennedy 2008).

\subsubsection{Controversy regarding the role of bacteria in chronic rhinosinusitis}

In contrast with the well-established roles of microbes in the etiology of acute sinusitis with Streptococcus pneumoniae, Moraxella catarrhalis and non typable Haemophilus influenzae strains as the most common pathogens involved, the exact roles of all of these microbes in the etiology of chronic sinusitis are uncertain. Until now, there have been many controversies concerning the microbial involvement in chronic sinusitis (Kilty \& Desrosiers, 2008; Thaler \& Kennedy, 2008).

It has been postulated that in many cases of chronic rhinosinusitis bacteria can be present only as non-pathogens. This conclusion arose from the observation, that the sinuses are not sterile as once taught. Also, the fact that poor correlation is observed between clinical findings, microbiology and antibiotic therapy confirmed the limited role of bacteria in chronic rhinosinustis (Post et al., 2004; van Cauwenberge et al., 2006).

Much of the disagreement may be explained by methodology used. Different studies used different sampling methods as well as different methods to detect bacteria and quantify bacterial load (culture vs. PCR). It is thought that these differences may not only affect the culture yield rate but also the type of organism isolated (Kilty \& Desrosiers, 2008).

Nowadays, the role of bacteria in chronic rhinosinusitis have gradually been revealed. Several theories raised to explain the patophysiology of this chronic disease. It is currently thought that chronic rhinosinusitis is an immunological inflammatory disease caused simultaneously or singly by several factors, such as: immune conditions, intrinsic upper airway factors, Staphylococcus aureus superantigens, and persistent biofilm presence and/or osteitis of the sinus wall (Bezerra et al., 2009). In this paper, the role of bacterial superantigens and biofilm will be overviewed.

\subsubsection{Bacterial superantigens}

The superantigen hypothesis of chronic rhinosinusitis suggests that bacterial toxins within the nose stimulate massive oligoclonal expansion of T-cell populations with subsequent eosinophil recruitment and tissue inflammation (Seiberling, Grammer, et al., 2005).

In the pathogenesis of chronic rhinosinusitis with nasal polyposis, this theory have been supported by several studies. Superantigens are microbial derived toxins capable of triggering massive $\mathrm{T}$ cell proliferation and activation. They have the ability to activate up to $30 \%$ of the T-cell population in contrast to the conventional antigen response, which 
activates only $0.01 \%$ of all $\mathrm{T}$ cells. In the acute setting superantigens may lead to the sudden and massive release of Th1 and Th2 cytokines which accounts for their acute toxicity (Llewelyn et al., 2002; Seiberling, Conley et al., 2005).

Evidence accumulates that Staphylococcus aureus colonizes a high percentage of patients with chronic rhinosinusitis with nasal polyposis. Staphylococcus aureus can secrete at least 19 different exotoxins capable of functioning as superantigens, triggering massive T-cell activation, and induces an overproduction of immunoglobulin E, as well as a severe possibly steroid-insensitive eosinophilic inflammation.(Zhang et al., 2005).

Understanding how superantigens overstimulate the immune system is crucial to set up rational therapeutics for chronic rhinosinusitis. Patients with eosinophilic chronic rhinosinusitis remain the most refractory to medical and surgical intervention (Seiberling, Conley et al., 2005).

\subsubsection{Bacterial biofilm}

One possible mechanism for the chronic nature of rhinosinusitis is the involvement of bacterial biofilms. Recent publications estimate that at least $65 \%$ of all chronic bacterial infections involve biofilms (Kilty \& Desrosiers, 2008; Post et al., 2004).

Biofilms are three-dimensional bacterial aggregates embedded together in the slimelike matrix composed of polysaccharides, nucleic acids and proteins (extracellular polymeric substances). Bacteria in biofilm are under different transcriptional regulation and are thus phenotypically different than free living bacteria. The vast majority of bacteria, regardless of species, exist within a biofilm, including those that are important in rhinosinusitis, such as Haemophilus influenzae, Streptococcus pneumoniae and Staphylococcus aureus (Kilty \& Desrosiers, 2008).

The formation of a bacterial biofilm occurs in several concurrent steps. The initiating event is the attachment of individual bacterial cells to a surface by weak reversible physical forces. Differentiation of the biofilm after attachment depends on cell-to-cell signaling, which facilitate the binding of other bacteria to the infected surface. This process initiates phenotypic changes within the bacteria to irreversibly secure the initial attachment.

The second stage involves irreversible attachment between specific microbial adhesins and the surface. One important element of this process is polysaccharide intracellular adhesion (PIA), that mediates the cell-cell interactions in some staphylococcal biofilms.

Cell aggregation into microcolonies and their division ensure the continued growth of the biofilm into complex structure. When biofilms reach their critical mass, single bacterium or aggregates of bacteria can disperse into the surrounding environment. After detachment bacteria can be redistributed to other areas of the host surface, where further biofilm growth can be initiated (Post et al., 2004).

Owing to its multicellular nature, biofilms provide bacteria with distinct advantages. An adventage that is extremely important clinically is that bacteria in biofilms are very resistant to antibiotics, capable of surviving antibiotic concentrations thousands of time greater than 
free living bacteria (Post et al., 2004). Also, biofilm formation makes the bacteria resistant to host defense mechanisms, because the aggregation of bacteria into biofilm cannot be phagocytized, humoral immune system is not effective against aggregated bacteria as well.

The same properties that make bacteria within biofilm resistant to antibiotics and to the attack of immune system also make it difficult to identify them in laboratory by routine methods. Bacterial biofilms have been found in patients with chronic rhinosinusitis by scanning electron microscopy (SEM), transmission electron microscopy (TEM), confocal scanning laser microscopy, or fluorescent in situ hybridization (FISH) successfully. The use of PCR-based techniques demonstrates a high detection rate of bacterial pathogens in chronic diseases when comparing with conventional culture technique (Kilty \& Destrosiers, 2008).

The fact that bacterial existence in the form of biofilm in probably preferred in chronic infections, there is growing evidence for the presence of bacterial biofilms in chronic rhinosinusitis (Kilty \& Desrosiers, 2008).

If bacterial biofilms are the cause of certain cases of chronic rhinosinusitis, then the treatment paradigms will have to be changed. Novel nonantimicrobial therapies may have clinical applications to prevent and destabilize biofilms.

\section{References}

Aanan, J.B. (2005). Current management of acute bacterial rhinosinusitis and the role of moxifloxacin. Clin. Infect. Dis. Vol. 41, pp. (S167-S176)

American Academy of Pediatrics: Clinical Practice Guideline: Management of Sinusitis (2001). Pediatrics, Vol. 108, pp. (798-808).

Baron, S. (1996). Medical microbiology, 4th edition. University of Texas Medical Branch at Galveston, ISBN - 10: 0-9631172-1-1, USA

Benninger, M.S. (2008). Acute bacterial rhinosinusitis and otitis media: changes in pathogenicity following widespread use of pneumococcal conjugate vaccine. Otolaryngol. Head Neck Surg. Vol. 138, No. 3, pp. 274-278

Benninger, M.S. \& Manz R. (2010). The impact of vaccination on rhinosinusitis and otitis media. Curr. Allergy Asthma Rep. Vol. 10, pp. (411-418)

Bezerra, T.F.P., Padna, F.G., Gebrim, E.M.M.S., Saldiva, P.H.N. \& Voegels, R.L. (2009). Biofilms in chronic rhinosinusitis with nasal polyps. Braz. J. Otolaryngol. Vol. 75, No. 6, pp. (788-793)

Brook, I., Foote P.A. \& Hausfeld J.N. (2006). Frequency of recovery of pathogens causing acute maxillary sinusitis in adults before and after introduction of vaccination of children with the 7-valent pneumococcal vaccine. J. Med. Microbiol. Vol. 55, No. 7, pp. (943-946)

Brook, I., Gooch, W.M., Jenkins, S.G., Pichichero, m.E., Reiner, S.A. \& Yamauchi T. (2000). Medical management of acute bacterial sinusitis recommendations of a clinical advisory committee on pediatric and adult sinusitis. Ann Otol Rhinol Laryngol Vol.109, pp. (120)

Fokkens, W.J., Lund, V.J., Mullol, J et al. (2007). European Position Paper on Nasal Polyps. Rhinology Vol. 45, Suppl. 20, pp. (1-139) 
Hadley, J.A. \& Siegret R. (2004). Clinician's manual on rhinosinusitis. Science Press Ltd, ISBN 1-85873-994-2, Italy

Hart, A.M. (2007). Diagnosis and management of acute respiratory infections: acute rhinosinusitis. J. Nurs. Pract. Vol.3, No.9, pp. (607-611)

Herrmann, BW \& Forsen, JW Jr (2004) Simultaneous intracranial and orbital complications of acute rhinosinusitis in children. Int J Pediatr Otorhinolaryngol Vol. 68, No. 5, pp. (619-625)

Hytönen, M., Atula, T. \& Pitkäranta, A. (2000) Complications of acute sinusitis in children. Acta Otolaryngol Suppl 543, pp.(154-157)

Kennedy, D.W. \& Thaler E.R. (1997). Acute vs. chronic sinusitis: etiology, management, and outcomes. Infect. Dis. Clin. Pract Vol. 2 Suppl 2, pp. (S 49-S 58)

Kilty, S.J., \& Desrosiers, M.Y. (2008). The role of bacterial biofilms and the pathophysiology of chronic rhinosinusitis. Curr. Allergy Asthma Rep. Vol. 8, pp.(227-233)

Llewelyn, M. \& Cohen, J. (2002). Superantigens: microbial agents that corrupt immunity. Lancet Infect Dis. Vol. 2, No. 3, pp. (156-162)

Mazur, E. (2010). Rational antibiotic therapy of acute upper respiratory tract infections. Pol. Merk. Lek. XXIX, Vol. 173, pp. (304-308)

McAlister, W.H., Parker, B.R., Kushner, D.C. (2000). Sinusitis in the pediatric population. In: ACR Appropriateness Criteria. Reston, VA: American College of Radiology.

Payne, S.C, \& Benninger, M.S. (2007). Staphylococcus aureus is a major pathogen in acute bacterial rhinosinusitis: a meta-analysis. Clin. Infect. Dis. Vol.45, pp. (121-127)

Plouin-Gaudon, I., Clement, S., Huggler, E , Chaponnier, C, Francosis, P., Lew, D., Schrenzel, J, Vaudaux, P. \& Lacroix, J.S. (2006). Intracellular residency is frequently associated with recurrent Staphylococcus aureus rhinosinusitis. Rhinology. Vol. 44, No. 4, pp. (249-254)

Post, J.Ch., Stoodley, P., Hall-Stoodley, L. \& Ehrlich, G.D. (2004). The role of biofilms in otolaryngologic infections. Curr. Opin. in Otolaryngol. Head Neck Surg., Vol. 12, pp.(185-190)

Ryan, D. (2008). Management of acute rhinosinusitis in primary care: changing paradigms and the role of intranasal corticosteroids. Prim. Care Resp. J. Vol. 17, No. 3, pp. (148-155)

Sande, M.A. \& Gwaltney, J.M. (2004). Acute community-acquired bacterial sinusitis: continuing challenges and current management. Clin. Infect. Dis. Vol. 39 Suppl 3, pp. (S151-S158)

Seiberling, K.A, Conley, D.B., Tripathi, A., Grammer, L.C., Shuh L, Haines, G.K., Schleimer, R.\& Kern, R.C. (2005). Superantigens and chronic rhinosinusitis: detection of staphylococcal exotoxins in nasal polyps. The Laryngoscope, Vol. 115, pp. (15801585)

Seiberling, K.A., Grammer, L. \& Kern, R.C. (2005). Chronic rhinosinusitis and superantigens. Otolaryngol. Clin. North Am. Vol. 38, No. 6, pp. (1215-1236)

Thaler, E.R. \& Kennedy D.W. (2008). Rhinosinusitis: a guide for diagnosis and management. Springer. ISBN: 978-0-387-73061-5, USA.

van Cauwenberge, P, van Hoecke, H. \& Bachert C. (2006) Pathogenesis of chronic rhinosinusitis. Curr. Allergy Asthma Rep. Vol. 6, pp. (487-494) 
Zhang, N., Gevaert, P., van Zele, T. Perez-Novo, C., Patou, J., Holtapplers, G., van Cauvenberge, P. \& Bachert C. (2005) An update on the impact of Staphylococcus aureus enterotoxins in chronic sinusitis with nasal polyposis. Rhinology. Vol. 43, No.3, pp. (162-168). 


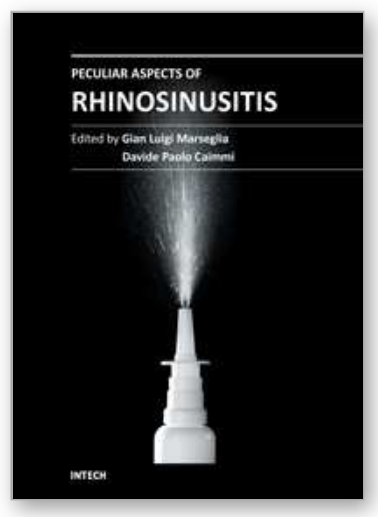

\author{
Peculiar Aspects of Rhinosinusitis \\ Edited by Dr. Gian Luigi Marseglia
}

ISBN 978-953-307-763-5

Hard cover, 112 pages

Publisher InTech

Published online 23, November, 2011

Published in print edition November, 2011

Rhinosinusitis has both a great practical interest and a broad significance due to the scientific complexity of the pathogenetic problems related to the disease, not yet completely resolved, and their implications for clinical treatment. This book highlights certain specific topics that usually are not clarified in other resources. The first chapter is devoted to the impoverished quality of life experienced by patients suffering from rhinosinusitis. The second chapter focuses on the microbiological aspects of rhinosinusitis, while the two subsequent chapters explain the peculiar aspects of chronic rhinosinusitis and of recurrent chronic rhinosinusitis. The first chapter of the second section of the book is dedicated to the imaging techniques used to visualize the nasal sinuses and the other to a medical topical type of treatment.

\title{
How to reference
}

In order to correctly reference this scholarly work, feel free to copy and paste the following:

Agnieszka Magryś, Jolanta Paluch-Oleś and Maria Kozioł-Montewka (2011). Microbiology Aspects of Rhinosinusitis, Peculiar Aspects of Rhinosinusitis, Dr. Gian Luigi Marseglia (Ed.), ISBN: 978-953-307-763-5, InTech, Available from: http://www.intechopen.com/books/peculiar-aspects-of-rhinosinusitis/microbiologyaspects-of-rhinosinusitis

\section{INTECH}

open science | open minds

\section{InTech Europe}

University Campus STeP Ri

Slavka Krautzeka 83/A

51000 Rijeka, Croatia

Phone: +385 (51) 770447

Fax: +385 (51) 686166

www.intechopen.com

\section{InTech China}

Unit 405, Office Block, Hotel Equatorial Shanghai

No.65, Yan An Road (West), Shanghai, 200040, China

中国上海市延安西路65号上海国际贵都大饭店办公楼 405 单元

Phone: +86-21-62489820

Fax: +86-21-62489821 
(C) 2011 The Author(s). Licensee IntechOpen. This is an open access article distributed under the terms of the Creative Commons Attribution 3.0 License, which permits unrestricted use, distribution, and reproduction in any medium, provided the original work is properly cited. 